Revista Brasileira de Agricultura Irrigada v.8, n. 2, p. 86 - 97, 2014

ISSN 1982-7679 (On-line)

Fortaleza, CE, INOVAGRI - http://www.inovagri.org.br

DOI: $10.7127 /$ rbai.v8n200227

Protocolo 227/14 - 30/11/2013 Aprovado em 16/03/2014

\title{
ENTUPIMENTO DE GOTEJADORES COM USO DE EFLUENTE DE ESGOTO SOB DOIS SISTEMAS DE FILTRAGEM
}

\author{
Guilherme Trimer Morata ${ }^{1}$, Geffson Figueredo Dantas ${ }^{2}$, Alexandre Barcellos Dalri ${ }^{3}$, \\ Luiz Fabiano Palaretti ${ }^{3}$, Rogério Teixeira de Faria ${ }^{3}$, Gilmar Oliveira Santos ${ }^{4}$
}

\begin{abstract}
RESUMO
Os sistemas de irrigação por gotejamento são os mais indicados para a irrigação com águas residuárias devido a elevada eficiência de aplicação e baixo risco de contaminação do produto agrícola. Objetivou-se avaliar o entupimento em diferentes gotejadores, utilizando efluente de esgoto tratado (EET) com dois tipos de filtros (tela e disco). Uma unidade operacional de irrigação localizada, com 12 linhas laterais (LL) e operando a $100 \mathrm{kPa}$, foi instalada com três diferentes modelos de gotejadores, denominados de (G1, G2 e G3). Como água de irrigação utilizou-se o EET nas condições puro e diluído em 50\%. As avaliações foram realizadas no início do experimento e a cada 80 horas de funcionamento do sistema, totalizando 5 avaliações $(0,80,160,240$ e 320h). Para avaliação do desempenho dos gotejadores, foram utilizados os seguintes parâmetros: coeficiente de variação de vazão (CVQ), vazão relativa (Qr) e grau de entupimento (GE). Os resultados obtidos permite concluir que não foi detectado efeito significativo do tempo de uso do gotejador na redução da vazão dos gotejadores; o CV elevou-se apenas para o modelo G3, mostrando maior amplitude desse coeficiente quando utilizado o EET foi diluído e não houve diferença no GE quando se utilizou filtro de tela e disco, para o EET diluído ou puro.
\end{abstract}

Palavras-chave: água residuária, entupimento, filtro

\section{CLOGGED DRIP EMITTERS WITH USE OF SEWAGE EFFLUENT FROM UNDER TWO SYSTEMS FILTERING}

\section{SUMMARY}

The drip irrigation systems are the most suitable for irrigation with wastewater due to high application efficiency and low risk of contamination of agricultural produce. This

\footnotetext{
${ }^{1}$ Graduando em Eng. Agronômica, UNESP/FCAV, Jaboticabal - SP. Email: guilherme_morata@hotmail.com

${ }_{2}^{2}$ Mestrando em Agronomia. UNESP/FCAV, Jaboticabal - SP. E-mail: geffson@ hotmail.com

${ }^{3}$ Prof. Dr., Departamento de Engenharia Rural UNESP/FCAV, Jaboticabal - SP. Email: dalri@fcav.unesp.br

${ }^{4}$ Doutorando em Agronomia. UNESP/FCAV, Jaboticabal - SP. E-mail:

gilmar_engambiental@yahoo.com.br
} 
study aimed to assess clogging in different emitters, using treated sewage effluent (TSE) with two types of filters (screen and hard). An operating unit of drip irrigation, with 12 lateral lines (LL) and operated at $100 \mathrm{kPa}$, was installed with three different models of drippers, called (D1, D2 and D3). As irrigation water used in the TSE pure conditions and diluted to $50 \%$. Evaluations were performed at baseline and every 80 hours of operation of the system, totaling 5 reviews $(0,80,160,240$ and 320h). Coefficient of variation of discharge (CVD) on flow rate (Fr) and degree of clogging (DC): To evaluate the performance of the emitters, the following parameters were used. The results support the conclusion that no significant effect of time of use of the dripper was detected in reducing the flow of the drippers, the CV rose only for the D3 model showing greater magnitude of this coefficient used when the TSE was diluted and there was no difference when using the DC screen and disk filter to EET diluted or pure.

Keywords: wastewater, clogging, filter

\section{INTRODUÇÃO}

A água é essencial à vida e as atividades humanas, sendo sua disponibilidade finita na natureza. A perspectiva de menor oferta desse recurso devido ao crescimento populacional, a expansão das fronteiras agrícolas e degradação dos corpos hídricos, exige um planejamento avançado por parte dos órgãos competentes.

Com o aumento populacional, consequentemente maior demanda por alimentos, torna-se necessário o uso de técnicas e manejo no setor agrícola, a fim de tornar as áreas mais produtivas. $\mathrm{O}$ uso de águas residuárias na irrigação vem sendo amplamente estudado e recomendado por diversos pesquisadores como Bucks (1979), Nakayama (1991), Ravina (1992), em todo o mundo como alternativa viável para atender as necessidades hídricas e, em grande parte, nutricionais das plantas. Entretanto, para que o reúso da água na agricultura se torne uma prática viável, é necessário aperfeiçoar as técnicas de tratamento, aplicação e manejo de águas residuárias, bem como dos efluentes de esgoto tratado (EET).

A utilização de EET na agricultura traz benefícios diretos, como o suprimento da demanda hídrica da planta (economia de água de boa qualidade) e o fornecimento de alguns nutrientes, como o nitrogênio, potássio e cálcio.

O problema do uso de efluentes em gotejamento é a alta susceptibilidade ao entupimento, como é relatado em diversos estudos específicos. Entupimentos parciais ou totais reduz a uniformidade de emissão e, em consequência, diminui a eficiência da irrigação e varia com as características do emissor e com a qualidade dos efluentes relacionada aos aspectos físicos, químicos e biológicos (CAPRA \& SCICOLONE, 2004).

Assim, este trabalho teve como objetivo avaliar o entupimento de gotejadores utilizando efluente de esgoto tratado puro (EET puro) e diluído (EET 50\%) associado a dois tipos de filtros. 


\section{MATERIAL E MÉTODOS}

O experimento foi conduzido na Fazenda Experimental da Faculdade de Ciências Agrárias e Veterinárias de Jaboticabal (FCAV-UNESP), localizado no município de Jaboticabal-SP (coordenadas geográficas $21^{\circ} 14^{\prime} 41,9$ ' $\mathrm{S}$ e $48^{\circ}$ 16 '25,2”), área pertence ao Departamento de Engenharia Rural, setor de irrigação. A Estação de Tratamento de Esgoto "Dr. Adelson Taroco", de onde foi coletado o efluente de esgoto tratado (EET) para utilização no experimento, localizase a cerca de 1,5 km da área experimental.

Em condições apropriadas e semelhantes a uma unidade operacional de irrigação localizada, foi instalado um ensaio com 3 modelos de gotejadores, dois tipos de filtros (tela e disco ambos de 120 mesh) e utilizou-se como água de irrigação o efluente de esgoto tratado (EET) $100 \%$ e diluído $50 \%$.

Para o armazenamento do efluente de esgoto foram utilizadas caixas de fibra de 15.000 e $3.000 \mathrm{~L}$ para o efluente puro e diluído $50 \%$, respectivamente. A caixa de $15.000 \mathrm{~L}$, de onde chegava o efluente bombeado da estação, alimentava a outra caixa feita a diluição na proporção de $50 \%$ de efluente e $50 \%$ água do poço artesiano, localizado próximo às caixas.

$\mathrm{Na}$ ligação das caixas e as bombas, foi utilizada mangueiras de polietileno. A pressurização do EET puro e diluído foi realizada por duas motobombas centrífugas de 0,5 CV cada. As linhas laterais, com os respectivos cavaletes estavam localizadas a $5 \mathrm{~m}$ dos reservatórios.

O EET passou pelo tratamento físico, o qual foi à filtragem por meio do filtro disco ou de tela, dependendo do tratamento. $\mathrm{O}$ experimento foi composto por 12 linhas laterais (LL) de $7,5 \mathrm{~m}$ de comprimento, com espaçamento entre as linhas laterais de $0,5 \mathrm{~m}$ e o espaçamento entre gotejadores de $0,3 \mathrm{~m}$. No final das linhas laterais foram instaladas válvulas de final de linha para promover a limpeza da tubulação quando o sistema era despressurizado. Foram instalados três modelos de gotejadores para o filtro de disco e os mesmos três gotejadores para o filtro de tela, ambos com efluente $100 \%$ e $50 \%$. A pressão de serviço nas linhas laterais foram mantidas em $100 \mathrm{kPa}$, e os modelos dos gotejadores foram distribuídos aleatoriamente.

Os gotejadores utilizados no experimento foram Durazio, Queen Gil e Chapin. As principais características técnicas encontram-se na Tabela 1.

Tabela 1. Principais características técnicas dos tubos emissores avaliados.

\begin{tabular}{ccccc}
\hline Gotejador & $\begin{array}{c}\text { Dispositivo de } \\
\text { compensação }\end{array}$ & $\begin{array}{c}\text { Espaçamento } \\
(\mathrm{m})\end{array}$ & $\begin{array}{c}\text { Diâmetro } \\
\text { do tubo } \\
(\mathrm{mm})\end{array}$ & $\begin{array}{c}\text { Vazão } \\
\left(\mathrm{L} \mathrm{h}^{-1} \mathrm{~m}^{-}\right.\end{array}$ \\
\hline Chapin & $\mathrm{NC}^{*}$ & 0,3 & 16,0 & 3,7 \\
Durázio & $\mathrm{NC}$ & 0,3 & 16,0 & 5,0 \\
Queen Gil & $\mathrm{NC}$ & 0,3 & 16,5 & 6,0 \\
\hline * NC = Não compensante & &
\end{tabular}

Com o objetivo de evitar possíveis especulações comerciais, positivas ou negativas, os gotejadores utilizados neste experimento foram codificados, uma vez que os ensaios conduzidos com EET não são normatizados. Nos resultados apresentados, os códigos dos modelos 
dos gotejadores não possuem nenhuma relação com a sequência dos emissores citados.

A água residuária utilizada no experimento, denominada de EET, foi pressurizada por meio de uma motobomba a diesel ao longo de $1,5 \mathrm{~km}$. Na estação de tratamento até ficar livre da contaminação inicial, o tratamento do esgoto passa pelas seguintes fases:

- Fase Preliminar: remoção dos resíduos sólidos através de gradeamento mecânico.

- Fase Primária: remoção da carga orgânica em que as bactérias realizam a digestão anaeróbica (livre de oxigênio)

- Fase Secundária (pós-tratamento): as lagoas facultativas finalizam o processo e removem os organismos coliformes

O EET contém significativas concentrações de nutrientes em sua composição conforme pode ser observado na Tabela 2.

Tabela 2. Análise físico-química do efluente de esgoto tratado utilizada no experimento.

\begin{tabular}{lcc}
\hline Parâmetro & Unidade & Concentração \\
\hline $\mathrm{pH}$ & ---- & 7,4 \\
$\mathrm{CE}$ & $\mu \mathrm{S}$ & 463,0 \\
N-total & $\mathrm{mg} \mathrm{L}$ & 67,3 \\
Ferro total & $\mathrm{mg} \mathrm{L}^{-1}$ & 0,36 \\
Potássio & $\mathrm{mg} \mathrm{L}^{-1}$ & 18,8 \\
DQO & $\mathrm{mg} \mathrm{L}^{-1}$ & 304,0 \\
Cálcio & $\mathrm{mg} \mathrm{L}^{-1}$ & 15,3 \\
Magnésio & $\mathrm{mg} \mathrm{L}^{-1}$ & 5,7 \\
Resíduos sedimentáveis & $\mathrm{mg} \mathrm{L}^{-1}$ & 0,5 \\
Óleos e Graxas & $\mathrm{mg} \mathrm{L}^{-1}$ & 45,0 \\
Sulfato & $\mathrm{mg} \mathrm{L}^{-1}$ & 20,7 \\
Manganês & $\mathrm{mg} \mathrm{L}^{-1}$ & 0,1 \\
Zinco & $\mathrm{mg} \mathrm{L}^{-1}$ & 1,0 \\
Sódio & $\mathrm{mg} \mathrm{L}^{-1}$ & 47,0 \\
Coliformes totais & $\mathrm{NMP} 100 \mathrm{~m} \mathrm{~L}^{-1}$ & 49.000 \\
\hline
\end{tabular}

A primeira avaliação realizada com água limpa ocorreu após a montagem do experimento, tempo igual à zero. A cada 80 horas eram realizados novos testes de vazão nos mesmos gotejadores, previamente identificados. Foram avaliados 10 gotejadores por linha lateral (LL), totalizando 120 gotejadores nas doze linhas laterais. Durante o teste a pressão no início da LL foi mantida a $100 \mathrm{kPa}$ com o auxílio de uma regulador de pressão. O sistema foi acionado diariamente até completar 40 horas de irrigação por semana, totalizando, no final do experimento, um tempo de uso dos gotejadores de 320 horas.

$\mathrm{Na}$ avaliação foram utilizados coletores dispostos abaixo dos gotejadores que coletavam o EET dos emissores. O tempo de coleta era de três minutos. Em seguida o volume coletado era pesado na balança eletrônica. Cada gotejador era isolado por barbantes para que fosse coletada corretamente a vazão do único gotejador selecionado e também para que não ocorresse interferência da vazão dos gotejadores adjacentes.

Para avaliação do desempenho dos gotejadores, foram utilizadas as seguintes características: vazão relativa (Qr) Equação 1, coeficiente de variação de vazão (CVQ) Equação 2 e grau de entupimento (GE) Equação 3.

$$
Q r=\frac{Q a}{Q i} 100
$$


Em que, Qr - vazão relativa, \%; Qi - vazão no início do experimento, $\mathrm{L} \mathrm{h}^{-1}$; Qa - vazão atual, $\mathrm{L} \mathrm{h}^{-1}$.

$$
C V Q=\frac{S}{q_{m}} 100
$$

Em que, CVQ - coeficiente de variação de vazão, \%; S - desvio-padrão da amostra, $\mathrm{L} \mathrm{h}^{-1}$; $\mathrm{q}_{\mathrm{m}}$ - vazão média da amostra, $\mathrm{L} \mathrm{h}^{-1}$.

$$
G E=\left(1-\frac{Q a}{Q i}\right) 100
$$

Em que, GE - grau de entupimento, \%;

Utilizou-se o delineamento inteiramente casualizado (DIC), com a utilização do teste F para análise de variância e de Tukey, para comparação de médias de vazões dos gotejadores. As análises estatísticas foram feitas por meio do programa Assistat.

\section{RESULTADOS E DISCUSSÃO}

\section{Vazão Relativa}

Para os gotejadores modelos G1 e G2 notase na Figura 1 que houve uma pequena variação acima de $100 \%$ no início, ou seja, de 0 a 80 horas, ficando praticamente constante de 80 a 320 h.

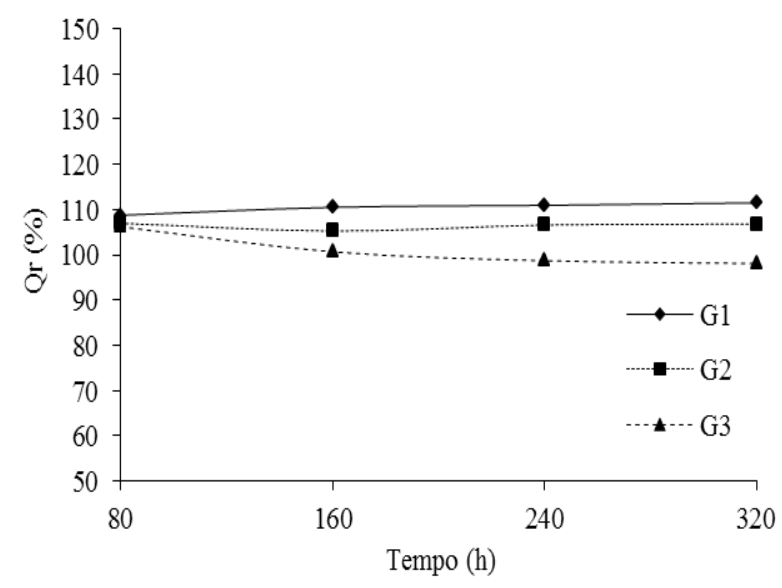

Figura 1. Vazão relativa (\%) dos modelos de gotejadores (G1, G2 e G3) com EET diluído em 50\% e filtro de tela.

Enquanto o modelo G3 apresentou pequena variação na Qr, sendo igual a 98,08\% no tempo de $320 \mathrm{~h}$, como pode ser observado na Figura 1. Esta variação foi de 7,6\% em relação ao tempo de $80 \mathrm{~h}$.

$\mathrm{Na}$ Figura 2, o modelo G1 manteve praticamente constante sua Qr durante as $320 \mathrm{~h}$, e seu valor no final no experimento foi de 109,35\%, ou seja, houve um aumento em sua Qr de 9,35\%. O modelo G2 e G3 teve um comportamento atípico no tempo de 240 horas, como pode ser observado. Isso pode ter ocorrido devido o aumento de pressão durante a coleta da vazão. Porém em 320 horas o Qr do G1 foi semelhante ao G2, enquanto o modelo G3 apresentou valor $14,72 \%$ menor, em relação ao G1. 


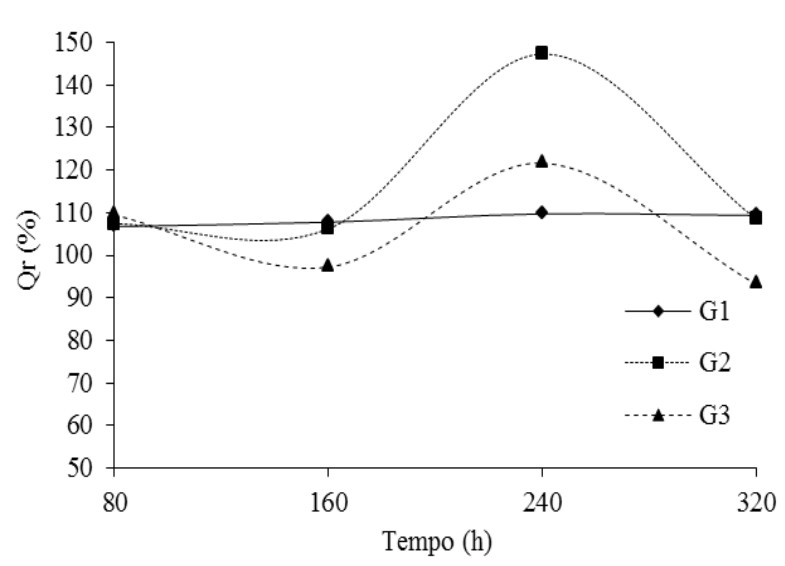

Figura 2. Vazão relativa (\%) dos modelos de gotejadores (G1, G2 e G3) com EET diluído em 50\% e filtro de disco.

Utilizando como água de irrigação o EET $100 \%$ combinado com de filtro de tela, observase na Figura 3, que no período entre 80 e 160 horas ocorreu uma redução da vazão relativa nos três modelos de gotejadores amostrados. A partir de 160 horas os valores mantiveram-se relativamente constantes para os três modelos, sendo G1 e G2 semelhantes e o modelo G3 aproximadamente $8 \%$ inferior.

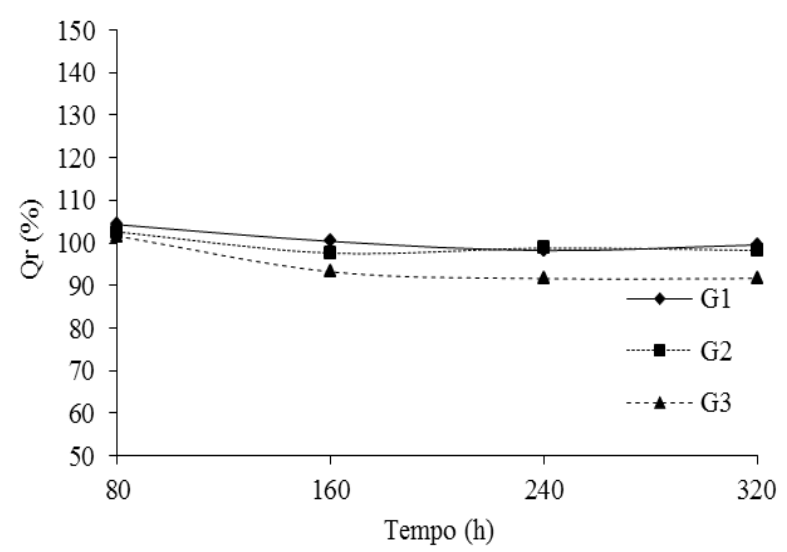

Figura 3. Vazão relativa (\%) dos modelos de gotejadores (G1, G2 e G3) com EET 100\% e filtro de tela.

$\mathrm{Na}$ Figura 4, a qual expressa à relação do tempo e a Qr, utilizando EET $100 \%$ e com filtro de disco, os modelos G1 e G2 apresentaram valores constantes de Qr durante todo o tempo, enquanto o modelo G3 teve uma redução de $6,8 \%$ entre 80 a 160 horas, e no restante do tempo manteve seu valor constante, próximo dos modelos G1 e G2.

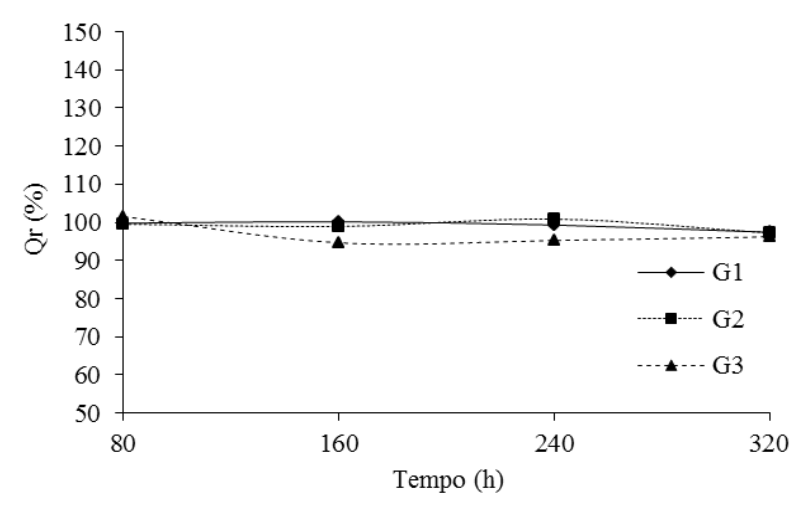

Figura 4. Vazão relativa (\%) dos modelos de gotejadores (G1, G2 e G3) com EET $100 \%$ e filtro de disco.

Quando sujeita aos dois tipos de filtro e duas qualidades do EET, não foi constatada alteração significativa nos valores da variável Qr. Mélo (2007) estudando o entupimento de gotejadores utilizando água com alto teor de cálcio e magnésio observou que a vazão relativa foi de $87,05 \%$ a $95,94 \%$ após 360 horas, resultado semelhante a este trabalho quando foi utilizado EET puro com filtro de tela.

\section{Coeficiente de Variação de Vazão}

De acordo com a Figura 5, o coeficiente de variação de vazão em relação ao tempo de funcionamento com uso de EET 50\% e filtro de tela, os modelos G1 e G2 apresentam valores baixos de coeficiente de variação de vazão e pouca variação desses valores durante o tempo 
total de funcionamento. Entretanto, o modelo G3 apresentou aumento nos valores do coeficiente de variação durante o tempo total do experimento, apresentando coeficiente de variação de $1,78 \%$ em 0 h e 22,20\% no tempo de $320 \mathrm{~h}$, o mesmo ocorreu no tratamento com EET diluído em $50 \%$ e filtro de disco apresentado na Figura 10, os modelos G1 e G2 mantiveram constantes e o modelo G3 apresentou grande variação no seu CVQ, no tempo de 320 chegou a $29,63 \%$.

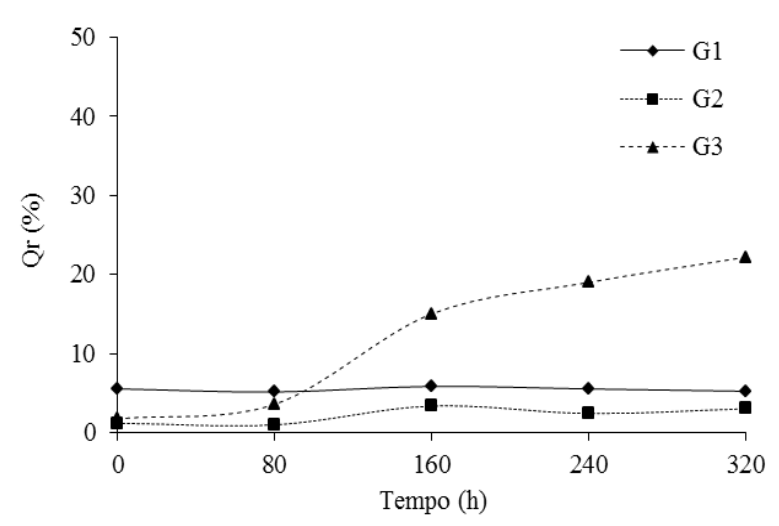

Figura 5. Coeficiente de variação (\%) dos modelos de gotejadores (G1, G2 e G3) com EET diluído em $50 \%$ e filtro de tela.

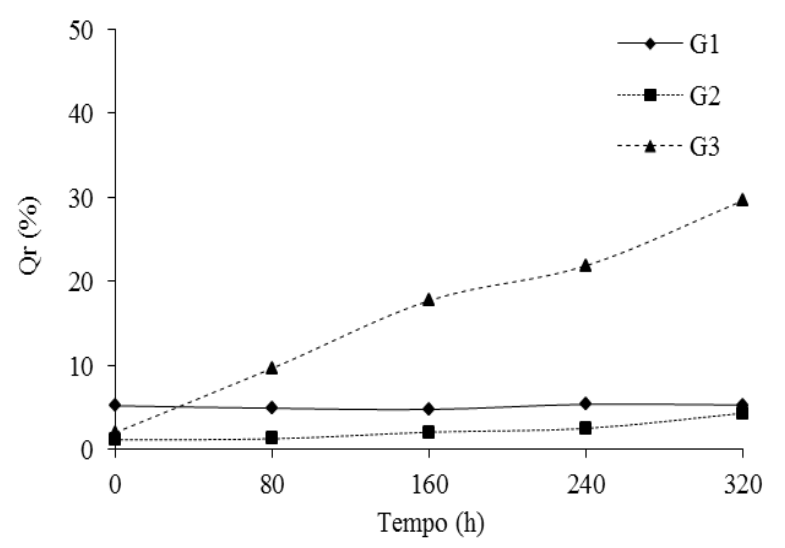

Figura 6. Coeficiente de variação $(\%)$ dos modelos de gotejadores (G1, G2 e G3) com EET diluído em $50 \%$ e filtro de disco.
Com base na Figura 7, com uso de EET puro e filtro de tela, os modelos G1 e G2 tiveram valores baixos de CVQ durante todo o ensaio, com uma pequena variação do modelo G2 em 160 horas. O modelo G3 apresentava valores baixos até 160 horas, mas em 240 horas houve um grande aumento no seu valor, alcançando $18,09 \%$, podendo ter ocorrido devido a uma variação da pressão no momento da avaliação e diminuindo em 320 horas para 9,14\%.

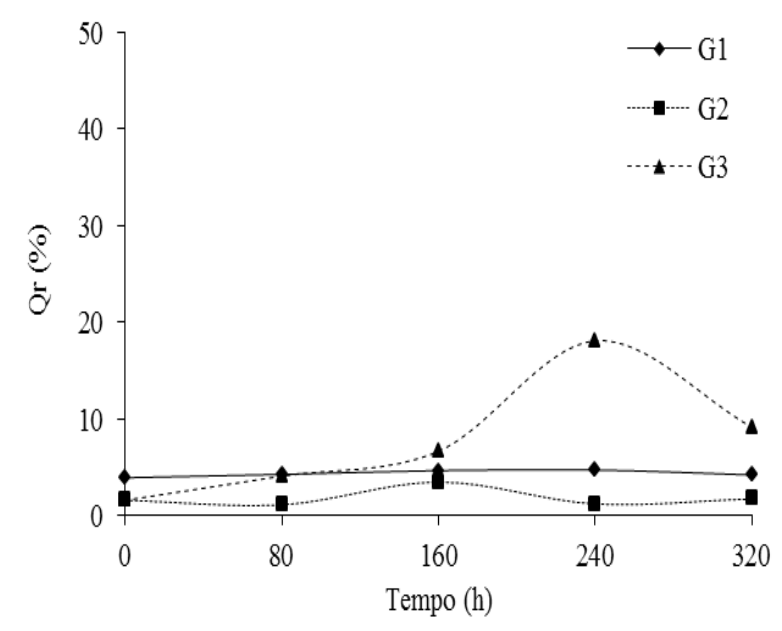

Figura 7. Coeficiente de variação (\%) dos modelos de gotejadores (G1, G2 e G3) com EET puro (100\%) e filtro de tela.

Na Figura 8, todos os modelos no tempo de 320 horas tiveram valores baixos de coeficiente de variação, sendo que o modelo G1 e G2 apresentaram valores constantes durante todo o ensaio e o modelo G3 apresentou variação durante todo o tempo. 


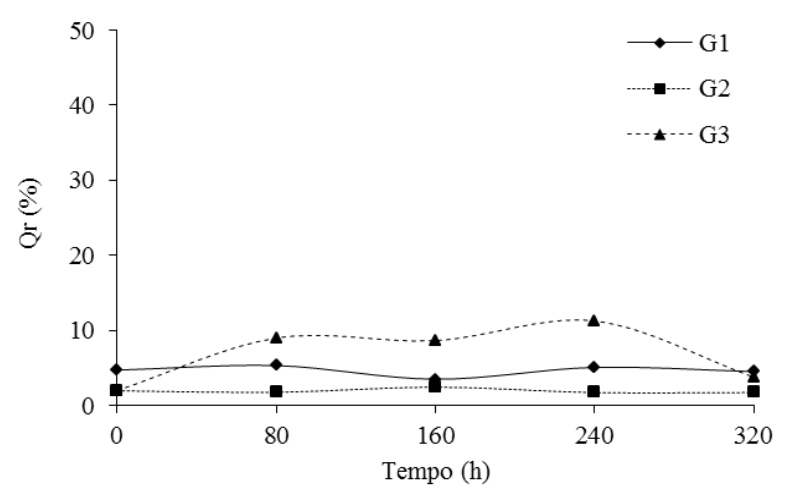

Figura 8. Coeficiente de variação (\%) dos modelos de gotejadores (G1, G2 e G3) com EET puro (100\%) e filtro de disco.

Os modelos G1 e G2 apresentaram valores de coeficiente de variação baixos $(<6 \%)$ em todos os tratamentos do experimento, assim melhor a uniformidade de aplicação dos emissores na linha, não houve muita variação entre estes dois modelos. Recomenda-se, portanto o uso de tubos emissores com arquitetura semelhante aos modelos G1 e G2 para o uso com água semelhante à utilizada neste experimento. Uma situação oposta ocorreu no modelo G3 que teve ampla variação do CVQ ao decorrer do tempo e apresentou valor de até 29,63\%. Gomes et al. (2013), em estudo realizado com o desempenho de gotejadores aplicando turfa gel, no dobro da quantidade recomendada pelo fabricante, via água de irrigação também chegou a valores de CVQ elevados, de até $80 \%$.

\section{Vazão média dos emissores}

A Tabela 3 apresenta os resultados da análise estatística da vazão dos emissores, observa-se que não ocorreu efeito do tempo no entupimento dos gotejadores, nos modelos G1 e
G3 quando usado filtro de tela e para o modelo G1 quando usado filtro de disco. Apesar do modelo G2 ter apresentado diferença estatística significativa quando usados os dois filtros, a diferença percentual da vazão foi de apenas $6,8 \%$ quando usado o filtro de tela e $8,27 \%$ quando usado o filtro de disco. Vale ressaltar que esta variação foi positiva, ou seja, a vazão do gotejador aumentou. Contrariando o resultado de algumas pesquisas, como a elaborada por Batista et al. (2011) com influência de diferentes qualidades de esgoto doméstico na vazão de gotejadores, a qual apresentou redução na vazão dos gotejadores operando com 500 horas e um modelo de gotejador.

Tabela 3. Análise estatística das médias das vazões $\left(\mathrm{L} \mathrm{h}^{-1}\right)$ dos emissores em função do tempo de aplicação quando operando EET diluído em $50 \%$.

\begin{tabular}{ccccccc}
\hline \multicolumn{3}{c}{ Filtro de tela } & \multicolumn{3}{c}{ Filtro de disco } \\
\hline \multirow{2}{*}{ Tempo } & \multicolumn{3}{c}{ Emissor } & \multicolumn{2}{c}{ Emissor } \\
\cline { 2 - 7 } & $\mathrm{G} 1$ & $\mathrm{G} 2$ & $\mathrm{G} 3$ & $\mathrm{G} 1$ & $\mathrm{G} 2$ & $\mathrm{G} 3$ \\
\hline $0 \mathrm{~h}$ & 1,42 & $1,32 \mathrm{~b}$ & 1,77 & 1,42 & $1,33 \mathrm{c}$ & $1,83 \mathrm{ab}$ \\
$80 \mathrm{~h}$ & 1,42 & $1,41 \mathrm{a}$ & 1,88 & 1,42 & $1,43 \mathrm{~b}$ & $2,00 \mathrm{ab}$ \\
$160 \mathrm{~h}$ & 1,45 & $1,39 \mathrm{a}$ & 1,78 & 1,43 & $1,41 \mathrm{~b}$ & $1,78 \mathrm{ab}$ \\
$240 \mathrm{~h}$ & 1,45 & $1,40 \mathrm{a}$ & 1,75 & 1,45 & $1,96 \mathrm{a}$ & $2,22 \mathrm{a}$ \\
$320 \mathrm{~h}$ & 1,46 & $1,41 \mathrm{a}$ & 1,74 & 1,45 & $1,44 \mathrm{~b}$ & $1,70 \mathrm{~b}$ \\
\hline $\mathrm{F}$ & $0,45^{\text {ns }}$ & $13,11^{* *}$ & $0,48^{\mathrm{ns}}$ & $0,66^{\mathrm{ns}}$ & $412,24^{* *}$ & $3,43^{*}$ \\
\hline $\begin{array}{l}\text { CV } \\
(\%)\end{array}$ & 5,42 & 2,44 & 14,55 & 5,06 & 2,59 & 18,61 \\
\hline As medias & & & & & & \\
\hline
\end{tabular}

As médias seguidas pela mesma letra, na coluna, não diferem estatisticamente entre si pelo Teste de Tukey ao nível de $5 \%$ de probabilidade (*) e $1 \%$ de probabilidade (**). ns: não significativo.

Na Tabela 4, nota-se que para os modelos G1 e G3, utilizando filtro de disco, não ocorreu efeito do tempo no entupimento dos gotejadores, 
enquanto todos os outros tratamentos demonstraram efeito significativo, mas com pequenas reduções nas vazões. O G1, com filtro de tela, teve a sua vazão reduzida em $4,4 \%$. No modelo G2 com filtro de disco ocorreu diferença significativa entre os tempos 0 e 320 horas e redução de 2,3\% na vazão.

Tabela 4. Análise estatística das médias das vazões $\left(\mathrm{L} \mathrm{h}^{-1}\right)$ dos emissores em função do tempo de aplicação quando operando EET puro.

\begin{tabular}{|c|c|c|c|c|c|c|}
\hline \multirow{3}{*}{ Tempo } & \multicolumn{3}{|c|}{ Filtro de tela } & \multicolumn{3}{|c|}{ Filtro de disco } \\
\hline & \multicolumn{3}{|c|}{ Emissor } & \multicolumn{3}{|c|}{ Emissor } \\
\hline & G1 & G2 & G3 & G1 & $\mathrm{G} 2$ & G3 \\
\hline $0 \mathrm{~h}$ & $1,35 \mathrm{a}$ & $1,28 \mathrm{~b}$ & $1,73 \mathrm{a}$ & 1,28 & $1,29 \mathrm{a}$ & 1,76 \\
\hline $80 \mathrm{~h}$ & $1,35 \mathrm{a}$ & $1,32 \mathrm{a}$ & $1,76 \mathrm{a}$ & 1,28 & $1,29 \mathrm{a}$ & 1,78 \\
\hline $160 \mathrm{~h}$ & $1,30 \mathrm{ab}$ & $1,25 \mathrm{~b}$ & $1,62 \mathrm{a}$ & 1,28 & $1,28 \mathrm{ab}$ & 1,66 \\
\hline $240 \mathrm{~h}$ & $1,27 \mathrm{~b}$ & $1,27 \mathrm{~b}$ & $1,59 \mathrm{a}$ & 1,27 & $1,31 \mathrm{a}$ & 1,67 \\
\hline $320 \mathrm{~h}$ & $1,29 \mathrm{ab}$ & $1,26 \mathrm{~b}$ & $1,59 \mathrm{a}$ & 1,25 & $1,26 \mathrm{~b}$ & 1,69 \\
\hline $\mathrm{F}$ & $3,91^{* *}$ & $9,81^{* *}$ & $2,87^{*}$ & $0,52^{\mathrm{ns}}$ & $4,87^{* *}$ & $1,65^{\mathrm{ns}}$ \\
\hline $\mathrm{CV}(\%)$ & 4,42 & 2,00 & 9,39 & 4,81 & 1,96 & 7,72 \\
\hline
\end{tabular}

As médias seguidas pela mesma letra, na coluna, não diferem estatisticamente entre si pelo Teste de Tukey ao nível de $5 \%$ de probabilidade (*) e $1 \%$ de probabilidade (**). ns: não significativo.

Operando com o EET puro, Tabela 4, observa-se uma redução da vazão de todos os modelos em função do tempo de funcionamento (0 a 320 horas), diferente do EET diluído 50\% que demonstrou aumento da vazão em função do mesmo tempo.

De acordo com os resultados o uso do EET puro pode provocar entupimentos mais severos e assim menores vazões ao longo do tempo.

\section{Grau de entupimento}

Ainda não consta em bibliografia especializada um índice que expresse a severidade do grau de entupimento de um gotejador. Para $\mathrm{GE}=0$ representa que não ocorreu entupimento e quando $\mathrm{GE}=100 \%$, o gotejador está totalmente obstruído e $\mathrm{GE}<0$, houve aumento da vazão.

Como não há norma para caracterizar a susceptibilidade ao entupimento do gotejador, será adotado como sugestão para esta pesquisa e futuras os índices apresentados na Tabela 5.

Tabela 5. Índices do GE sugeridos para quantificar o a severidade do grau de entupimento nos gotejadores.

\begin{tabular}{cc}
\hline GE $(\%)$ & Classificação \\
\hline$<0$ & Sem entupimento \\
$0-10$ & Baixo \\
$10-40$ & Médio \\
$40-90$ & Alto \\
$90-100$ & Muito Alto \\
\hline
\end{tabular}

Observa-se na Figura 9A que somente no modelo G3 nos tempos de 240 e 320 horas ocorreu entupimento de 1,28 e $1,92 \%$ respectivamente. Enquanto nos modelos G1 e G2 ocorreram valores negativos, que indicam que não demonstraram entupimento dos gotejadores e sim aumento da vazão. O mesmo ocorre no tratamento com EET $50 \%$ com filtro de disco (Figura 9B). Nesse caso, houve um entupimento 
classificado como "baixo" após 320 h de uso no modelo G3. Na Tabela 6 encontra-se a classificação do grau de entupimento (GE) sugerido nesse trabalho para os demais tubos emissores.
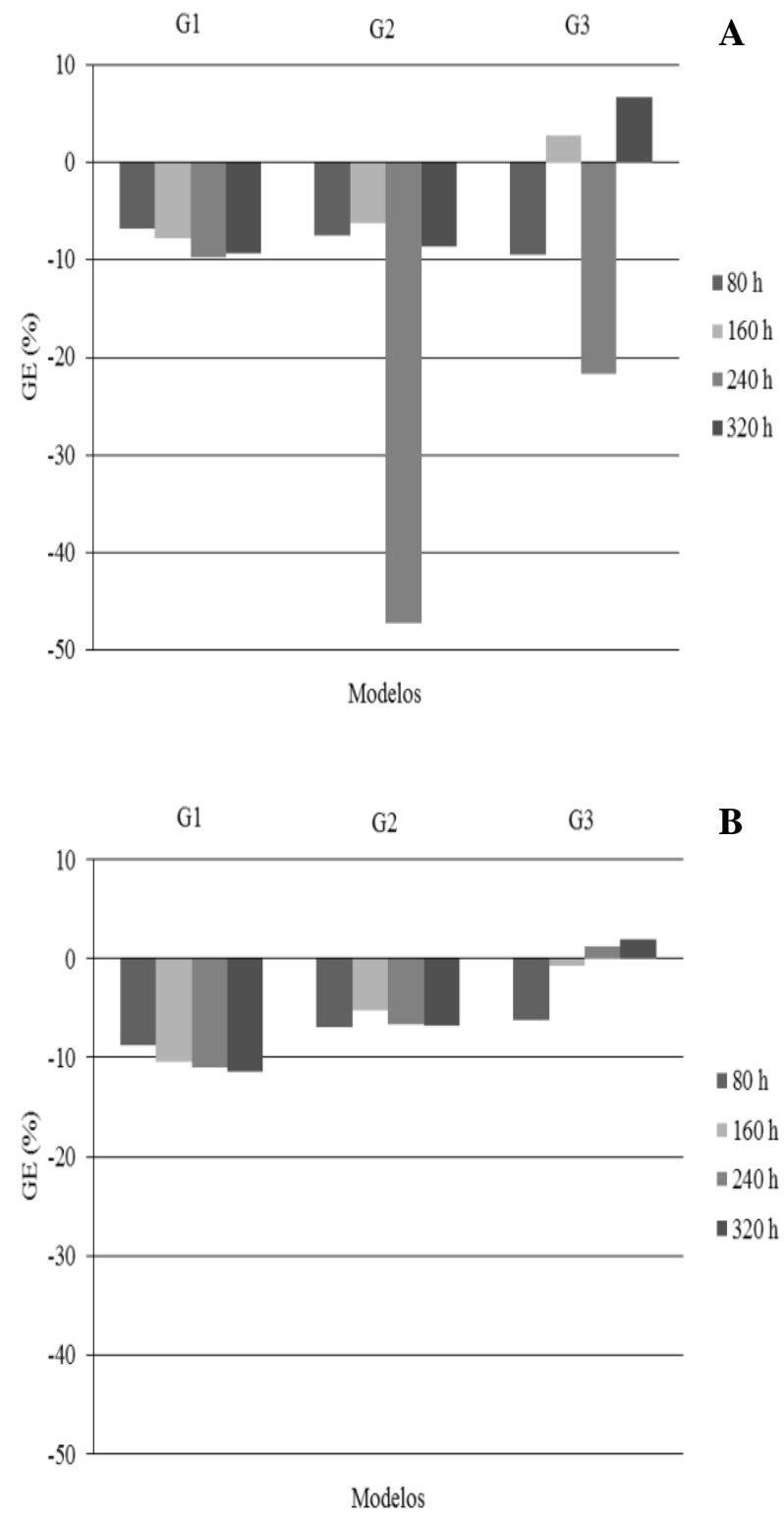

Figura 9. (A) Grau de entupimento (\%) dos modelos de gotejadores (G1, G2 e G3) com o EET diluído em $50 \%$ e uso do filtro de tela e (B) uso do filtro de disco.
Tabela 6. Classificação do GE dos gotejadores sujeitos ao uso de EET $50 \%$.

\begin{tabular}{ccc}
\hline Tratamento & Modelo & Classificação \\
\hline \multirow{3}{*}{$50 \%$ Tela } & G1 & Sem entupimento \\
& G2 & Sem entupimento \\
& G3 & Baixo \\
\hline \multirow{2}{*}{$50 \%$ Disco } & G1 & Sem entupimento \\
& G2 & Sem entupimento \\
& G3 & Baixo \\
\hline
\end{tabular}

Na Figura 10A, com o uso de EET puro, apresenta os valores do GE nos três modelos de gotejadores, sendo maior no modelo G3 a partir de 160 horas. Nos modelos G1 e G2 observou valores baixos, alcançando valores maiores próximos a $2 \%$.
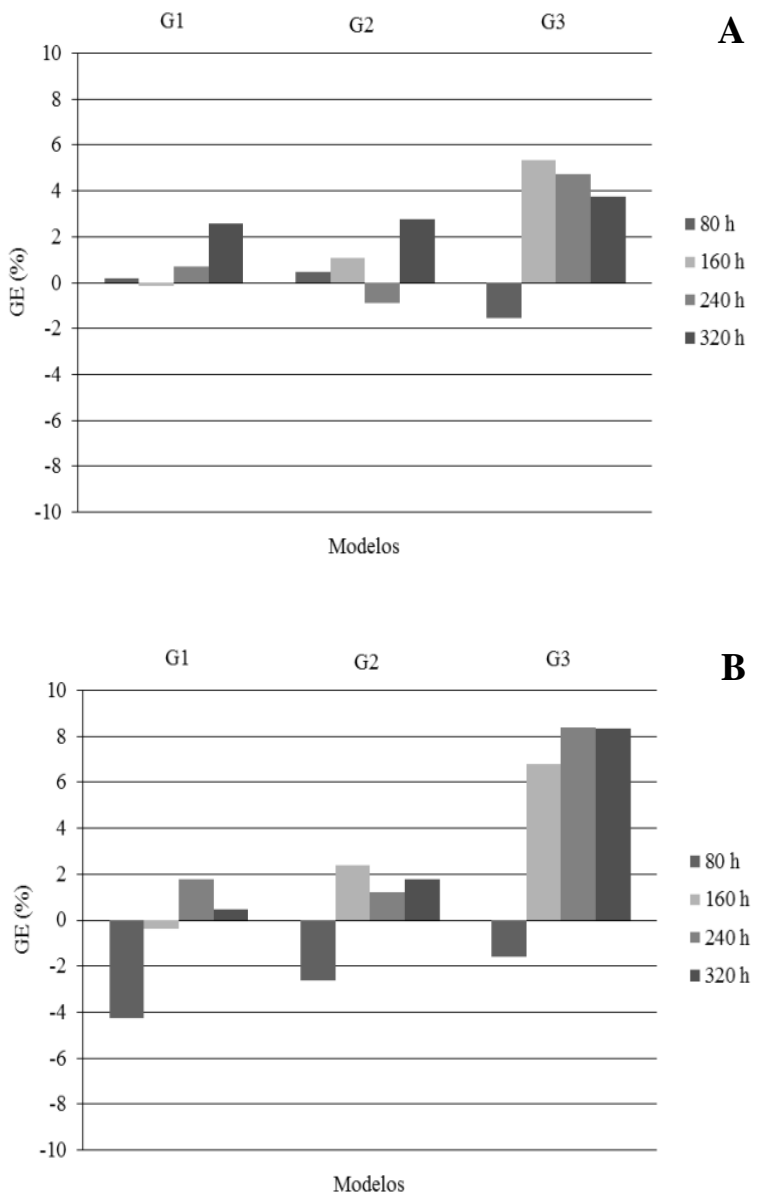

Figura 10. (A) Grau de entupimento (\%) dos modelos de gotejadores (G1, G2 e G3) com uso do EET puro (100\%) uso do filtro de tela e (B) uso do filtro de disco. 
O modelo G3 apresentou maior suscetibilidade ao entupimento com EET puro, no qual com 320 horas de uso chegou a $8,34 \%$. Entupimentos com o uso de EET puro já eram esperados, devido à alta concentração do mesmo, por outro lado o GE em 320 horas foi inferior a $10 \%$, classificando-o com GE "baixo".

Na Figura 10B, utilizando EET puro com filtro de disco, nota-se que também houve entupimento dos três modelos de gotejadores, destacando o modelo G3, que a partir de 160 horas de uso apresenta maiores valores de entupimento. Os modelos G1 e G2 apresentaram maiores valores em 320 horas de 2,58\% e 2,77\%, entretanto menor que no modelo G3.

Uma comparação entre o uso do EET diluído e o EET puro, notou-se que o GE foi maior quando foi utilizado o EET puro.

O grau de entupimento negativo indica aumento da vazão dos gotejadores. Em trabalho realizado por Cararo (2004), utilizando 15 modelos de gotejadores com água residuária oriunda de tratamento secundário, foi verificado aumento nas vazões $(\mathrm{GE}<0)$ dos gotejadores em 373 horas de funcionamento, resultados semelhantes aos observados nesta pesquisa.

Analisando a classificação proposta do GE (Tabela 7), nota-se que os três modelos de gotejadores apresentaram a mesma classificação, embora o modelo G3 apresentou maior suscetibilidade ao entupimento, pois o GE encontrado foi maior.
Tabela 7. Classificação do GE dos gotejadores sujeitos ao uso de EET puro.

\begin{tabular}{lcc}
\hline Tratamento & Modelo & Classificação \\
\hline \multirow{3}{*}{$100 \%$ Tela } & G1 & Baixo \\
& G2 & Baixo \\
& G3 & Baixo \\
\hline \multirow{2}{*}{$100 \%$ Disco } & G1 & Baixo \\
& G2 & Baixo \\
& G3 & Baixo \\
\hline
\end{tabular}

Foi observado que o maior valor de GE ocorreu na utilização do EET puro e com uso de filtro de tela. $\mathrm{O}$ uso do sistema de filtro de disco, nos dois tipos de efluente, apresentou melhores resultados comparado com filtro de tela, o GE foi menor nos sistemas com uso de filtro de disco.

\section{CONCLUSÕES}

Os resultados obtidos no presente trabalho permitem as seguintes conclusões:

a) O uso do EET com a respectiva qualidade físico-química pode ser recomendado o uso de gotejadores de características semelhante, pois não foi detectado entupimento severo nos gotejadores até $320 \mathrm{~h}$ de uso.

b) O CVQ elevou-se apenas para o modelo G3, mostrando maior amplitude desse coeficiente quando utilizado o EET 50\%.

c) Não ocorreu efeito significativo do tempo de uso do gotejador na redução da vazão dos mesmos. 
d) Não ocorreu diferença no GE quando se utilizou filtro de tela ou disco, para o EET diluído ou puro.

\section{REFERÊNCIAS BIBLIOGRÁFICAS}

BATISTA, R. O.; OLIVEIRA, R. A.; SANTOS, D. B.; MESQUITA, F. O.; SILVA, K. B. Suscetibilidade ao entupimento de gotejadores operando com água residuária de suinocultura. Water Resources and Irrigation Managementt, v. 2, n. 1, p. 19-25, 2013.

BUCKS, D.A.; NAKAYAMA, F.S.; GILBERT, R.G. Trickle irrigation water quality and preventive maintenance. Agricultural Water Management, v. 2, n. 2, p. 149-162, 1979.

CAPRA, A.; SCICOLONE, B. Emitter and filter tests for wastewater reuse by drip irrigation. Agricultural Water Management, v. 68, n. 2, p. 135-149, 2004.

CARARO, D. C. Manejo de irrigação por gotejamento para aplicação de água residuária visando a minimização do entupimento de emissores. Piracicaba, 2004.
129 f. Tese (Doutorado) - Escola Superior de Agricultura Luiz de Queiroz, Universidade de São Paulo, ESALQ.

GOMES, L. O.; GOMES, A. W. A.; OLIVEIRA, R. C.; TEIXEIRA, M. B.; BARROS, A. C.; COELHO, R. D.; Desempenho de gotejadores em função da aplicação de turfa gel na água de irrigação. Revista Brasileira de Agricultura Irrigada, v. 7, n. 1, p. 27-41, 2013.

MÉLO, R. F. de. Dinâmica e controle do entupimento de gotejadores em função de precipitados químicos e fitoplâncton. Piracicaba, 2007. 189 f. Tese (Doutorado) Escola Superior de Agricultura Luiz de Queiroz, Universidade de São Paulo, ESALQ.

NAKAYAMA, F. S.; BUCKS, D. A. Water quality in drip/trickle irrigation: A review. Irrigation Science, v. 12, n. 41, p. 187-192, 1991.

RAVINA, I.; PAZ, E.; SOFER, Z.; MARCU, A.; SCHISCHA, A.; SAGI, G. Control of emitter clogging in drip irrigation with reclaimed wastewater. Irrigation Science, v. 13, n. 3, p. 129-139, 1992. 